\title{
Micro plastic Pollution in Coastal Water and Beach Sediments at Adyar and Cooum River Estuaries in Chennai Coast
}

\author{
G. V S S Rajesh, Ramesh S, N. Nagalakshmi
}

\begin{abstract}
Plastics having number of applications all over the world and its great usage lead to rapid increase in plastic production and disposal. Around 400 million tons of plastics produced per year worldwide, out of this only $18 \%$ of plastics recycled that has led to its poor disposal practice because discharged plastics overcome in the environment for several 100 years either in their original or fragmented form. The fragmentation of particles are caused by several factors like wind currents, wave currents, abrasions etc., leading to various sizes which are classified as macro- $(\geq 25 \mathrm{~mm})$, meso- $(<25 \mathrm{~mm}-5 \mathrm{~mm})$ micro- $(<5 \mathrm{~mm}-1 \mu \mathrm{m})$ and further Nano-plastics $(<1 \mu \mathrm{m})$.This study manly focusses on quantification of Micro plastics which can be identified in different shapes such as spherical beads (pellets), films, fragments, foam, fibers etc., and are generally composed of polyethylene (0.91-0.97 $\mathrm{g} / \mathrm{mL})$, polypropylene $(0.94$ $\mathrm{g} / \mathrm{mL})$, polyvinyl chloride $(1.4 \mathrm{~g} / \mathrm{mL})$, and polystyrene $(1.05 \mathrm{~g} / \mathrm{mL})$. For this analysis of micro plastic existence, the water samples have been collected from two locations such as Adyar and Cooum estuaries. 10 samples have been collected each location and carried over to the laboratory for FTIR-Spectrometer (Fourier Transform Infrared Spectrometer) analysis along with the protocol laid by the NOAA. Typical infrared spectrum covers between $2.5 \mu \mathrm{m}$ to $25 \mu \mathrm{m}\left(4000 \mathrm{~cm}^{-1}\right.$ to $\left.400^{\mathrm{cm}^{-1}}\right)$.
\end{abstract}

Keywords: Micro plastics, Quantification, polymers, NOAA protocol, FTIR

\section{INTRODUCTION}

In these last few years, global annual demand for plastics has gradually growing. Plastics are well designed for a number of uses as a flexible medium weight solid and easily translucent materials [1]. Their deposition in surface waters is also increased significant use of plastics resulting in contaminated waters and oceans creating chemical imbalances in aquatic environment..This topic has become increasingly interested in environmental research, with the study of evidences addressing accumulation of plastic litters and its

Revised Manuscript Received on June 22, 2020.

* Correspondence Author

G. V S S RAJESH*, Civil department of engineering, SRM Institute of Science and Technology, Chennai, India. Email: govadarajesh05@gmail.com

RAMESH S, Civil department of engineering, SRM Institute of Science and Technology, Chennai, India. Email: rameshs@srmist.edu.in

Dr. N. NAGALAKSHMI, Civil department of engineering, SRM Institute of Science and Technology, Chennai, India. Email: nagalakr@srmist.edu.in

(c) The Authors. Published by Blue Eyes Intelligence Engineering and Sciences Publication (BEIESP). This is an open access article under the CC BY-NC-ND license (http://creativecommons.org/licenses/by-nc-nd/4.0/) consequences, one such example for deposition of plastics in ocean environment is deposited plastics in north pacific gyre and this incidence has been listed as topic of higher priority in marine sciences. The vibrant characteristics of sea (coastal)waters depends on physio chemical standards of fresh water bodies, estuaries and lagoons with adjacent oceanographic features. Estimation and restoration of local coastal and aquatic pollution is also one of the complex environmental and Eco toxicological issue that remains difficult and emerging. Precise assessments of environmental impacts related to manufactured plastics cannot be quantified. But most of those generated annually are found to enter the atmosphere as waste deposits and thus they have to be measured and evaluated on a regular basis to incorporate new ideas to eliminate or prevent the rise in ecological imbalances. Plastics are long chain monomers of higher molecular mass and lower density, extremely elastic and structurally sound. Plastics are cost effective, durable and are chemically resistant these properties of plastics add on and make them non-biodegradable. Besides these, their low expense, outstanding properties of oxygen / moisture inhibitors, bio stiffness and light weight render them outstanding packaging material. Conventional materials such as glass metal and papers are substituted by quick, effective, equal or superior plastic packaging. Close to one-third of plastic resin production if converted into customer's product packaging that includes disposable single items [1]. Plastics can usually be classified into different classes based on different criteria (i) the primary classification is normally based on the polymer's chemical structure (i.e. polymer backbone and its side chain) (ii) they can be graded according to the chemical process followed in plastics synthesis. Plastics are considered to be the best packaging materials as they are highly resistant to chemical attacks, durable and flexible, often clear and particularly inert to oxygen and moisture entry. therefore, their increased usage and depositions are considered as one of major leading contaminants of marine pollution.

Plastics that are estimated as sources of contamination can be broadly differentiated based on their size as micro, meso and macro plastics. NOAA (National Oceanic Atmospheric Administration) classified plastics of size lesser than $5 \mathrm{~mm}$ as micro plastics. Micro plastics are smaller fragments of plastics that are considered as threat to marine pollution the size of micro plastics considered in this study ranges from 0.3 to 5 mille meter. Micro plastics occur in different shapes like beads, which are considered as primary pollutants as they are highly resistant to deformation because of their size, thickness and properties.

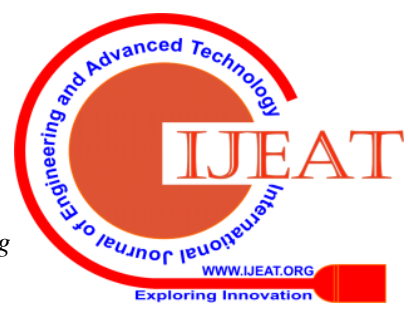




\section{Micro plastic Pollution in Coastal Water and Beach Sediments at Adyar and Cooum River Estuaries in Chennai Coast}

These plastics are observed to persist in the same size before and after entering into eco-system. films, fragments, foam, fibers etc. are grouped as secondary pollutants as they are distinguished based on the parental pollutants from which they are degraded. This paper by usual laboratory testing procedures attempts to address the presence of micro plastic debris in the estuary points of Adayar and Cooum rivers of Chennai, Tamil Nadu.

\section{MATERIALS AND METHODS}

\subsection{Materials}

Customized sieves of varying pore diameter $5 \mathrm{~mm}, 1 \mathrm{~mm}$ and $0.3 \mathrm{~mm}$ are made out of stainless-steel material. analytical grade Sodium chloride $(\mathrm{NaCl}=58.44)$ and glass microfiber filters if Grade-B was purchased from vital science industry. The samples are analyzed for presence of plastics using the absorbance values from FTIR Spectrometer and thereby they are sent to SEM analysis at Nano Technology Research Center, SRM Institute of Science and Technology, Kattankulathur, Chennai.

\subsection{Experimental procedure}

\subsubsection{Water sample}

Water Samples collected along the estuary line of Adyar and Cooum of nearly 1 liter in quantity are initially set to sieving process where debris of size greater than $5 \mathrm{~mm}$ are discarded and debris greater than $0.3 \mathrm{~mm}$ are collected on sieves. these remaining solids on the sieves are transferred by rinsing samples by distilled water and those particles that are of greater size $(>5 \mathrm{~mm})$ are discarded and are not considered for further test procedures. The sample collected after sieving are set for drying procedure where they are placed in oven in beaker at $90^{\circ} \mathrm{C}$ for span of 24 hours. The mass of the dried samples are found out and then set for wet peroxide oxidation where $\mathrm{FeSO}_{4}$ and $\mathrm{H}_{2} \mathrm{O}_{2}$ are added to the sample to degrade the organic matter present in it at the end of this step $\mathrm{NaCl}$ of $5 \mathrm{M}$ is prepared and add to these samples and from there as next step samples are sent for density separation. The effluent samples are sent for FTIR analysis for confirmation of presence of plastics. As a next step these samples are sent to SEM Analysis for visual observation of those plastics that are present on the filters.

\subsection{2 sand samples}

Sand samples are collected from the top surface of a square frame with dimensional size of $0.5 \mathrm{~m} \times 0.5 \mathrm{~m}$ and about $800 \mathrm{~g}$ in quantity from different locations along the estuary line. The collected samples are oven dried for a period of $24 \mathrm{hr}$ at a temperature of $90^{\circ} \mathrm{C}$ and sieved through customized sieves of pore sizes $5 \mathrm{~mm}, 3 \mathrm{~mm}$ and $0.1 \mathrm{~mm}$. The prepared samples are sent for density separation where the lighter weight particles are made to float on the top surface by addition of $5 \mathrm{M} \mathrm{NaCl}$ solution and from this step the floating materials are collected from the top surface and are set to wet peroxide oxidation, where $\mathrm{FeSO}_{4}$ and $\mathrm{H}_{2} \mathrm{O}_{2}$ are added to the samples containing organic and inorganic debris and heated to a temperature of $60^{\circ} \mathrm{C}$ to degrade the organic contents present in the samples. This reacts vigorously, to control the rate of reaction distilled water is added to slower the reaction rate and the procedure is continued till the organic content is completely degraded. As final step of laboratory analysis these are set to density separation where from these solution samples the sand sediments are separated from liquid particles and the top floating lighter density particles are filtered through glass microfiber filters of Grade B to capture the debris then the filters are sent to FTIR analysis for confirmation of presence of plastics and then to SEM analysis for visual observation of those plastics that are present on the filters.

\section{RESULTS AND DISCUSSION}

There are various types of plastic litters of different sizes and shapes observed during the collection of water and beach sediment samples that are generally visible to naked eye. Besides these there are minute size micro plastics confined between $5 \mathrm{~mm}$ to $0.3 \mathrm{~mm}$ both visible and not visible to human eye that are present in samples that are analyzed by laboratory methods. The samples are undergone through all the steps of drying sieving, density separation, wet peroxide oxidation again density separation and then finally through filtration are sent to FTIR analysis for further confirmation of plastic litter present in the samples compared with the beach sediment samples water samples are found to have lesser or almost absence of micro plastics this laboratory test fully does not confirm that there are no micro plastics in water of these considered Adyar and Cooum estuary points.

Of the 30 samples obtained, 14 samples consisting of microplastics were found and as a special case 4 samples consisting of main and secondary microplastics were found. Here primary microplastics found are mostly spherical pellets(beads) used in packing purposes and they might have reached water sources through depositions into river but by count primary microplastics are lesser in number when compared with secondary microplastics. In comparison to these main microplastics, certain plastic litters known as secondary microplastics such as fishing nets, damaged plastic materials, and parts of plastics used for recycling and labeling purposes ... etc. These are higher in quantity in beach sediments but are in trace quantity in water samples. As we know that beach sediments are composite by nature and are evident by the samples collected from various points of sampling area. On an average the samples are found to have $9.075 \%$ of waste litters comprising shells, organic matter, plastics, food waste...etc. where by the plastic load is very minute $0.012 \%$ by weight. 



Figure 1 transmittance values indicating presence of plastics in sample

\section{CONCLUSION}

Plastics presence is more in beach sediments when compared to water samples and also by count and by weight primary micro plastics are very less compared to secondary micro plastics. Besides the considered size of micro plastics there are plastics of greater size which may further degrade and turn into micro plastics which may further cause ecological damage, this count is not constant as we know that estuaries have vibrant characteristics which depends on various factors. The origins of such plastics detected may be estimated as deposition of plastics into rivers and shore region, reduction of fishing networks, usage of plastics for packaging, etc. to monitor the load of plastics recommendations such as implementing numerous clean-up projects, avoidance of single-use plastics recycling and proper disposal of plastics can also minimize plastic load on the aquatic environment.

\section{REFERENCES}

1. Andrady AL. Microplastics in the marine environment. Marine pollution bulletin. 2011 Aug 1;62(8):1596-605.

2. Auta HS, Emenike CU, Fauziah SH. Distribution and importance of micro plastics in the marine environment: a review of the sources, fate, effects, and potential solutions. Environment international. 2017 May 1; 102:165-76.

3. Claessens M, De Meester S, Van Landuyt L, De Clerck K, Janssen CR. Occurrence and distribution of micro plastics in marine sediments along the Belgian coast. Marine pollution bulletin. 2011 Oct 1;62(10):2199-204.

4. Cole M, Lindeque P, Halsband C, Galloway TS. Microplastics as contaminants in the marine environment: a review. Marine pollution bulletin. 2011 Dec 1;62(12):2588-97.

5. Coppock RL, Cole M, Lindeque PK, Queirós AM, Galloway TS. A small-scale, portable method for extracting microplastics from marine sediments. Environmental Pollution. 2017 Nov 1; 230:829-37.

6. do Sul JA, Costa MF. The present and future of microplastic pollution in the marine environment. Environmental pollution. 2014 Feb 1; 185:352-64.

7. Law KL, Thompson RC. Microplastics in the seas. Science. 2014 Jul 11;345(6193):144-5

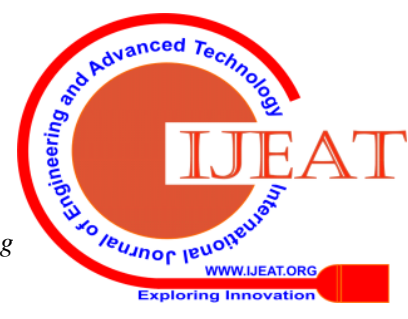




\section{Micro plastic Pollution in Coastal Water and Beach Sediments at Adyar and Cooum River Estuaries in Chennai Coast}

8. $\mathrm{Ng} \mathrm{KL}$, Obbard JP. Prevalence of microplastics in Singapore's coastal marine environment. Marine Pollution Bulletin. 2006 Jul 1;52(7):761-7.

9. Ryan PG, Moore CJ, van Franeker JA, Moloney CL. Monitoring the abundance of plastic debris in the marine environment. Philosophical Transactions of the Royal Society B: Biological Sciences. 2009 Jul 27;364(1526):1999-2012.

10. Wang J, Tan Z, Peng J, Qiu Q, Li M. The behaviors of micro plastics in the marine environment. Marine Environmental Research. 2016 Feb 1; 113:7-17.

11. Wright SL, Thompson RC, Galloway TS. The physical impacts of micro plastics on marine organisms: a review. Environmental pollution. 2013 Jul 1; 178:483-92.

12. Reddy MS, Basha S, Adimurthy S, Ramachandraiah G. Description of the small plastics fragments in marine sediments along the Alang-Sosiya ship-breaking yard, India. Estuarine, Coastal and Shelf Science. 2006 Jul 1;68(3-4):656-60.

13. Raj U, Kumar P, Galhotra A. Microplastics-All we know till now and the way out. Indian Journal of Community and Family Medicine. 2018 Jan 3;4(2):19.

14. Jayasiri HB, Purushothaman CS, Vennila A. Quantitative analysis of plastic debris on recreational beaches in Mumbai, India. Marine pollution bulletin. 2013 Dec 15;77(1-2):107-12.

15. Karthik R, Robin RS, Purvaja R, Ganguly D, Anandavelu I, Raghuraman R, Hariharan G, Ramakrishna A, Ramesh R. Microplastics along the beaches of southeast coast of India. Science of The Total Environment. 2018 Dec 15; 645:1388-99.

16. Reddy MS, Basha S, Adimurthy S, Ramachandraiah G. Description of the small plastics fragments in marine sediments along the Alang-Sosiya ship-breaking yard, India. Estuarine, Coastal and Shelf Science. 2006 Jul 1;68(3-4):656-60.

17. Sruthy S, Ramasamy EV. Microplastic pollution in Vembanad Lake, Kerala, India: the first report of microplastics in lake and estuarine sediments in India. Environmental pollution. 2017 Mar 1; 222:315-22.

18. Veerasingam S, Saha M, Suneel V, Vethamony P, Rodrigues AC, Bhattacharyya S, Naik BG. Characteristics, seasonal distribution and surface degradation features of microplastic pellets along the Goa coast, India. Chemosphere. 2016 Sep 1; 159:496-505.

\section{AUTHORS PROFILE}

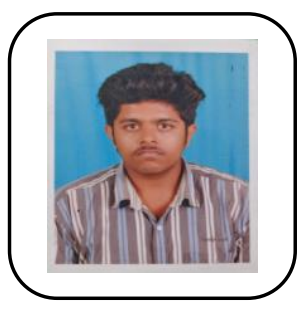

G V S S Rajesh received the B. tech degree in civil engineering from $\mathrm{KL}$ College of Engineering, India in 2014-2018 and doing M. Tech. degree in Environmental Engineering from SRM Institute of Science and Technology, India in 2018-2020. His research interests are in effects and reduction of plastic pollution in environment.

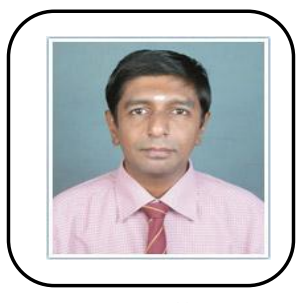

Mr. S. Ramesh

Assistant Professor (O. G.)

Assistant Professor of Department of Civil Engineering, SRM Institute of Science and Technology, Tamilnadu, India, has graduated in Meenakshi Krishnan Polytechnic, April 1997, received the B.Tech. degree in Civil April 2000, Engineering from SRM Engineering College,

Tamil Nadu, India and took his post graduate on Environmental Engineering from Sathyabama University, April 2011. His Ph. D degree is on Environmental Engineering from SRM Institute of Science and Technology, Tamilnadu, India. His current research interests are in area of micro plastic pollution in marine environment. Member in Indian Science Congress Association (ISCA), 2017. Member in Indian Society for Technical Education (ISTE), 2018

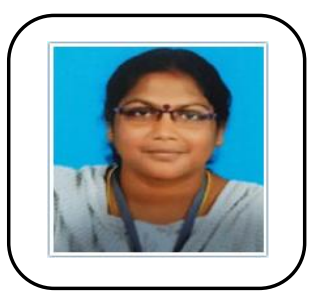

Dr. R. Nagalakshmi

Associate Professor

Associate Professor of Department of Civil Engineering, SRM Institute of Science and Technology, Tamilnadu, India, has graduated in 2002, received the M.Sc. degree in Oceanography and Coastal Area Studies from Alagappa University, Tamilnadu. She completed her Ph. D degree on Remote Sensing \& GIS from Anna University, 2009 and took her post graduate on Coastal Management from Anna University, 2014. Her current research interests are in Focus Group Discussion with Mangrove Dependent People in Vedaranyam Wetland Areas, East Coast of Tamilnadu, India' under review in Elsevier journal of ocean and coastal management. She participated as 'Organizing Secretary' in the First International Conference on Environmental Sustainability with Green Technology conducted by the Department of Civil Engineering, Meenakshi Sundararajan Engineering College during 15-17 March 2010. 